Mehmet Akif Ersoy Üniversitesi Fen Bilimleri Enstitüsü Dergisi 10(2): 166-175 (2019)

The Journal of Graduate School of Natural and Applied Sciences of Mehmet Akif Ersoy University 10(2): 166-175 (2019)

Araştırma Makalesi / Research Paper

\title{
Yeşil Yol Planlama: Denizli Pamukkale İlçesi Örneği
}

\author{
Murat ZENGIN 1*, Duygu DOĞAN 1 , Sinem ÖZDEDE \\ ${ }^{1}$ Pamukkale Üniversitesi, Mimarlık ve Tasarım Fakültesi, Peyzaj Mimarlığı Bölümü, Denizli \\ Geliş Tarihi (Received): 19.08.2019, Kabul Tarihi (Accepted): 30.10.2019 \\ $\square$ Sorumlu Yazar (Corresponding author*): mzengin@pau.edu.tr \\ (C) +902582962544 皿 +902582962614
}

\begin{abstract}
ÖZ
Yeşil yollar kentte ekolojik, kültürel ve rekreasyonel alanları birbirine bağlayan çizgisel ögelerdir. Yeşil alt yapı sisteminin önemli bir parçası olan ve 1867'de Frederick Law Olmsted'in "Zümrüt Gerdanlık" kavramıyla başlayan yeşil yol kavramı, kentlerde ekolojik ve kültürel devamlıı̆ı̆n yanı sıra rekreasyonel gereksinimlere de cevap vermektedir. Yeşil yollar, kentsel planlama ve tasarım çalışmalarında doğal ve kültürel kaynakların koruma-kullanım dengesi kapsamında ele alınmasında önemli mekânsal ögelerdir. Çalışma alanı olarak Denizli İli Pamukkale İlçesi kent merkezi, iki ölçekte ele alınmıştır. Üst ölçek çalışmada, kentteki önemli yeşil alanlar, rekreasyon alanları, su yüzeyleri, akarsular ve yollar (bisiklet, yürüyüş, bağlantı vb.) değerlendirmeye alınmış ve kentsel bir yeşil yol güzergahı önerilmiştir. Alt ölçekte ise, bu güzergah içerisinde mekânsal yeşil yol tasarım önerileri geliştirilmiştir. Bu kapsamda yapılan çalışma ile Pamukkale ilçesinde yer alan doğal ve kültürel kaynaklar koruma-kullanım dengesi çerçevesinde ele alınarak yeşil altyapı sistemi desteklenmiştir. Çalışma ile bir yandan kentteki yeşil dokunun sürekliliği sağlanırken, bir yandan da kentte yaşayanlar için alternatif rekreasyon alanlarının oluşumuna katkı sunulmuştur.
\end{abstract}

Anahtar Kelimeler: Yeşil yol, yeşil altyapı, planlama, rekreasyon, Denizli

\section{Greenway Planning: An Example of Pamukkale District, Denizli-Turkey}

\begin{abstract}
Greenways are linear elements that linking ecological, cultural and recreational areas in the city. The concept of the greenway, which started with the conception of "Emerald Necklace" by Frederick Law Olmsted in 1867, is an important part of the green infrastructure system, besides responds to the recreational requirements as well as ecological and cultural continuity in cities. Greenways are important spatial elements on natural and cultural resources within the scope of conservation-use balance in urban planning and design studies. As the study area, Pamukkale district center of Denizli Province has been studied on two scales. In the upper scale study, important green areas, recreation areas, water surfaces, rivers and roads (cycling, walking, connection etc.) were evaluated and an urban greenway route was proposed. On the lower scale, spatial greenway design proposals were developed within this route. In this context, natural and cultural resources in Pamukkale district were taken into consideration within the framework of protectionusage balance and green infrastructure system was supported. While the continuity of the green pattern in the city was provided, as well as, it was contributed to the formation of alternative recreation areas for the inhabitants of the city.
\end{abstract}

Keywords: Greenway, green infrastructure, planning, recreation, Denizli 


\section{GíRiş}

Yeşil yol fikrinin tarihi kökleri 100 yıldan daha eskidir (Zube, 1995). Kavram ilk olarak 1867'de Frederick Law Olmsted'in "Zümrüt Gerdanlık" kavramıyla başlar. Yeşil yol kavramı ilk ortaya çıkışı ve evriminde kentsel peyzaj formu olarak üç farklı aşama veya "kuşak" tanımlanabilir;

1. Nesil Yeşil Yollar (1700 - yaklaşık 1960): Bulvarlar ve park yolları ile kentsel alanlardaki ilk bağlantılardır.

2. Nesil Yeşil Yollar (yaklaşık 1960 - 1985): Bunlar iz odaklı, öncelikle rekreasyonel amaçlı, yeşil yollar ve kent dokusundaki nehirlere, akarsulara, köprülere, tren raylarına ve diğer koridorlara erişim sağlayan doğrusal parklardır. Bu yeşil yolların çoğunun önemli bir vurgusu motorsuz seyahattir.

3. Nesil Yeşil Yollar (yaklaşık 1985 - günümüze): Bunlar, kentsel güzelleştirme ve rekreasyonun yanı sıra, vahşi yaşamın ihtiyaçlarına, sel hasarlarının azaltılmasına, su kalitesine, eğitim ve diğer altyapı gereksinimlerine yönelik olarak ortaya çıkan "çok amaçlı" yeşil yollardır (Searns, 1995).

Yeşil yola ilişkin pek çok tanım yapılmıştır. Ahern (1995)'e göre yeşil yollar, ekolojik, rekreasyonel, kültürel, estetik veya sürdürülebilir arazi kullanımı kavramıyla uyumlu diğer amaçlar da dahil olmak üzere birçok amaç için planlanmış, tasarlanmış ve yönetilmiş doğrusal unsurlar içeren ağlardır. Fabos (1995) karayolları ve demiryolları gibi birbirlerini bağlanan, değişik genişliklerdeki koridorlar olarak tanımaktadır. İtalyan Yeşil Yollar Birliğine göre ise yeşil yollar "çevresel açıdan iyi ve motorsuz trafiği sağlanmış, insanlarla peyzaj kaynakları arasında (doğal, tarihsel, kültürel vb.) bağlantı kuran ve hem kentsel hem de kırsal alanlardaki "yaşam merkezleri" (kamu ofisleri, spor ve eğlence tesisleri vb.) dir (Associazione Italiana Greenways, 1999; Toccolini ve ark., 2006). Yeşil yollar, daha geniş alanlardaki açık alanların birbirine bağlanması ve doğal kaynakların korunması, yaşam alanlarının korunması, bitkilerin ve hayvanların hareketinin sağlanması ve doğrusal rekreasyon, alternatif ulaşım ve doğa çalışması için fırsatlar sunmak için ayrılan doğal koridorlardır (Maryland Department of Natural Resources, 2003; Bryant, 2006). Tanımlardan da anlaşılacağı gibi yeşil yollar farklı amaçlar için tasarlanmış doğrusal ögelerdir.

Bu kapsamda yeşil yollar araştırmacılar tarafından farklı şekillerde kategorize edilmiştir (1) kentsel nehir kenarındaki yeşil yollar; (2) yolları ve parkurları içeren rekreasyonel yeşil yollar (3) ekolojik olarak önemli koridorlar; (4) doğal ve tarihi rotalar; (5) kapsamlı yeşil yol sistemleri veya ağları olmak üzere temelde beş tür yeşil yol bulunmaktadır (Little, 1990; Ryder, 1995). Fabos (1995) yeşil yolları (1) önemli ekolojik sistemler ve doğal sistemlerle oluşturulan yeşil yollar (2) rekreasyonel yeşil yollar (3) tarihi miras ve kültürel değerleri içeren yeşil yollar olmak üzere üçe ayırmaktadır (Doğan, 2012).

Yeşil yolların avantajları aşağıdaki şekilde özetlenebilir;

- Yeşil yolların iyi bir şehir yapısı oluşturmada önemli rolleri bulunmaktadır. Yeşil yollar sürdürülebilir peyzajlar için parçalanma, arazi bozulumu, kentsel büyüme ve kontrolsüz arazi kullanımı değişikliğine karşı mücadele etmede bir araçtır (Sijmons, 1990; Kerkstra ve Vrijlandt, 1990; Van Buuren, 1991; Ahern, 1995; Viles ve Rosier, 2001).

- Tarımsal alanlardaki bitkisel çitler ve nehir kenar çizgisiyle oluşturulan yeşil yollar tarımsal alanlarda yüzey akışı ve erozyonun önlenmesi, artan besin geri dönüşümü ve mikro iklimsel (rüzgar hızını düşürerek depolamaya izin verirken, atmosferik ve toprak neminin yükselmesini sağlar) yararlar sağlamaktadır (Forman ve Godron, 1986; Fedorowick, 1993).

- Yeşil yollar ekolojik ve kültürel kaynakları, bir tür peyzaj sinerjisi olarak parçaların toplamından daha değerli ve daha yüksek kullanımı olan bir tür ağa veya sisteme bağlama yeteneğine sahiptir (Zube, 1995; Viles ve Rosier, 2001).

- Yeşil yollar, bir kişinin kendini iyi hissetme duygusunu geri kazanabileceği ve bir dizi aktif ve pasif rekreasyon gereksinimini ve isteğini keşfedip tatmin edebileceği sağlıklı ortamlar sağlayabilir (Fabos, 1995).

- Yürüyüş ve bisiklet gibi doğrusal rekreasyon biçimleri için çevresel ve sosyal işlevi yerine getirebilir. Ayrıca yeşil yol izlerinin rekreasyon potansiyeli, büyük açık arazi alanlarının az olduğu ve genellikle kamu kullanımı için satın alınamayacak kadar pahalı olduğu metropol bölgelerde önemlidir (Gobster, 1995).

- Akarsu koridorları, terkedilmiş demiryolları, işlevini yitirmiş kanallar ve yollar, elektrik hatları ve sokaklar potansiyel yeşil yollar olarak tanımlanmaktadır (Little, 1990; Porter ve Hastings, 1991; Gobster, 1995).

- Yeşil yolların yeşil bantlar olarak işlev gördüğü yerlerde, gelişimi kontrol eder, kirliliği azaltır ve peyzajı geliştirir ve korur (Smith, 1993; Viles ve Rosier ,2001).

- Yeşil yollar, doğa eğitimi için alanlar sağlayabilmektedir (Groome, 1990; Viles ve Rosier, 2001). Mülkiyet değerlerinin arttırıması (yeşil kuşakların içinde ve yanında), turizmin gelişmesi, istihdam ve ticari fırsatların yaratılması gibi ekonomik faydalar, yeşil yollardan elde edilen diğer faydalardır (Viles ve Rosier, 2001). 
Yeşil yollar hızlı nüfus artışı, sanayileşme vb. sebeplerle büyüyen ve yeşil dokusunu kaybeden kentlerde önemli bir kavramdır. Kent ve çevresindeki önemli ekolojik ve kültürel alanların devamlılığını sağlarken, kentte yaşayanlar için de sınırlı olan rekreasyonel alanlar açısından alternatifler sağlamaktadır. Bu kapsamda yapılan çaIışma ile kentteki önemli yeşil alanlar, rekreasyon alanları, turizm ve dinlenme alanları, yollar akarsu ve su yüzeylerine bağlı olarak Denizli Pamukkale ilçesi örneğinde bir yeşil yol planının oluşturulması amaçlanmıştır. Doğal ve kültürel kaynakların sunmuş oldukları olanaklar koruma-kullanma dengesi çerçevesinde yeşil yol planına dahil edilerek kentin yeşil altyapı sisteminin desteklenmesi hedeflenmiştir.

\section{MATERYAL VE YÖNTEM}

Çalışma alanı sınırlarını, Denizli kenti Pamukkale ilçesinde bulunan Üçgen Kavşağı, Valilik, Çamlık Kent Ormanı, Pamukkale Üniversitesi, Bağbaşı-Teleferik ile Recep Yazıcıoğlu Gölet'ini birbirine bağlayan ulaşım sistemi oluşturmaktadır (Şekil 1). Çalışmada, arazi çalışmalarından elde edilen fotoğraflar, Pamukkale ilçesi 1/5000 Nazım İmar Planı, 1/1000 Uygulama İmar Planı, ilçe mülkiyet haritası, Google Earth uydu görüntüleri ile ArcGIS, AutoCad, Photoshop yazilımlarından materyal olarak yararlanılmıştır.
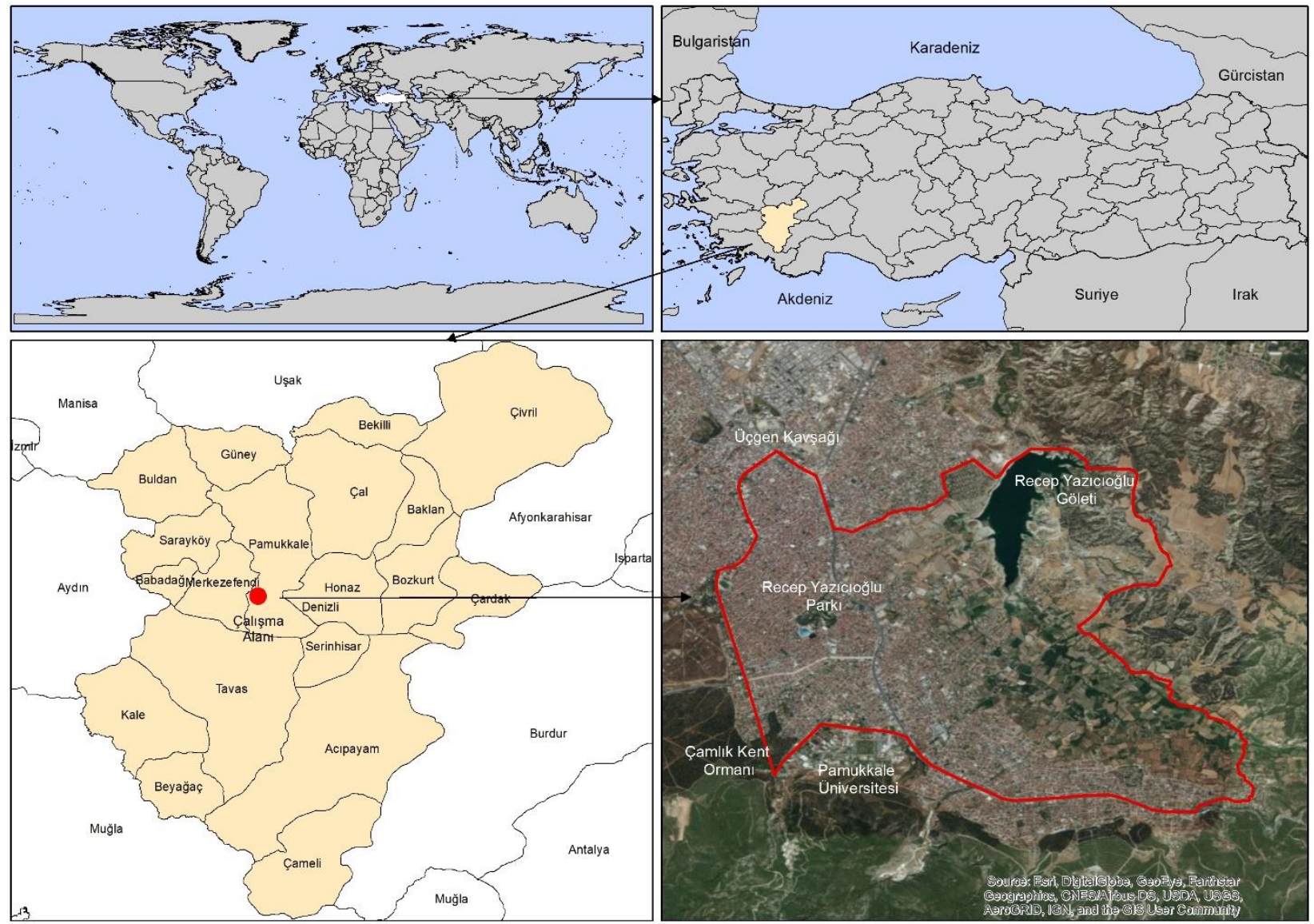

Şekil 1. Konum haritası

Çalışmanın yöntemi beş aşamadan oluşmaktadır. Illk aşamada literatür taraması yapılmıştır. Bu literatür taramasında; yöntemin belirlenmesine ilişkin olarak, yeşil yol planlama konusunda yapılmış olan yerli ve yabancı kaynaklar incelenmiştir. Bu kaynakların sunduğu yaklaşımlar; avantaj ve dezavantajları irdelenerek, araştırma alanına uygulanabilirliği açısından değerlendirilmiştir. Bu aşamada alanına ilişkin veri toplanmasının yanı sıra literatür taraması ve arazi çalışmaları yapılmıştır. Elde edi- len verilerin büyük bir bölümü arazi çalışmaları ve fotoğraflama çalışmalarına dayanmaktadır. İkinci aşmada çaIışma alanına ilişkin sorun ve olanakların belirlenmesi amacıyla, SWOT Analizi yapılmıştır. Sorun ve olanakların belirlenip, mevcut durumun yorumlandığı bu analiz, alana ait oluşturulan veri tabanına dayalı olarak yapılmıştır. Üçüncü aşamada çalışma alanındaki odak noktalar belirlenmiştir. Dördüncü aşamada belirlenen odakların çevresindeki doğal izler ortaya konulmuş, kent için- 
deki çeşitli kullanımlar ve izler takip edilmiş, mülkiyet deseni de dikkate alınarak analizler yapılmıştır. Son aşamada potansiyel yeşil yol belirlenmiş ve değerlendirmeler yapılarak oluşturulan yeşil yol planının uygulanabilirliğini sağlamak için bazı öneriler geliştirilmiştir.

Güzergahlar belirlenirken; Recep Yazıcıoğlu Göleti ve su toplama havzası, Çamlık Parkı, Recep Yazıcıoğlu Parkı, Bağbaşı kent içi parkları, Recep Yazıcıoğlu Göleti çevresindeki kırsal yerleşim alanları ve içerisindeki sosyo-kültürel mekanlar, Pamukkale Üniversitesi Kampüs alanı, Forum Çamlık AVM ve açık hava tiyatrosu, yeşil dokusu güçlü askeri alan, kentin güneyinde manzara noktası oluşturan teleferik ve yeşil sistemin devamlılığını sağlayan önemli kavşaklar ve refüj düzenlemeleri,
Denizli-Antalya karayolu üzerinde yer alan bisiklet yollarını dikkate alan önemli iz ve odaklar olarak alınmıştır.

\section{BULGULAR VE TARTIŞMA}

Çalışma kapsamında ilk olarak literatür taraması ve arazi çalışmaları yapıımıştır. Çalışmalar sırasında alandaki doğal ve kültürel ögelerin yerleri tespit edilmiştir. Arazi çalışmaları sırasındaki gözlemlere dayanarak alandaki sorun ve olanakları belirlemek için GZTF (SWOT) analizi yapılmıştır (Tablo 1). Yapılan analiz sonucu, alanda tespit edilen doğal ve kültürel ögelerle birlikte değerlendirilmiştir. Değerlendirme sonucunda önemli iz, odaklar ve odakların etki bölgeleri tespit edilmiştir.

Tablo 1. GZTF (SWOT) analizi

\begin{tabular}{l|l|}
\hline Güclü Yönler & Zayıf Yönler \\
-Kentsel doku ve yeşil yol ile ilişkili, bir göletin var- & -Kırsal nitelikli alanlarda yapılaşmanın artması \\
lığı & -Altyapı yetersizliği \\
-Gölet ile bağlantılı akarsu, suyolları, kanallar ve & -Çevresel kirlilik unsurları \\
derelerin olması & -Araç sayısı ve trafik yoğunluğu \\
-Suya dayalı rekreasyonel aktivitelere olanak sun- & -Güvenlik problemleri \\
ması & -Yapılaşmanın kentin doğusundaki tarım alanla- \\
-Tarımsal peyzaj deseni açısından zengin yapı ser- & rına baskı yapması \\
gilemesi & -Gölet ve çevresinde kirliliğin artması \\
-Yeme, içme ve eğlence mekanlarının bulunması & \\
-Yeşil yol altyapısını destekleyen büyük parklar, & \\
AVM, kampüs alanı, teleferik, kent ormanı vb. rek- & \\
reasyon alanlarının olması & \\
-Şehirlerarası karayolu ulaşımının çalışma alanın- \\
dan geçiyor olması
\end{tabular}

Öncelikle çalışma kapsamında planlanan yol güzergâhı, alan kullanımlarına ve etkiledikleri bölgeye göre 7 bölgeye ayrılmıştır (Şekil 2);

1. Bölge: Barındırdığı kullanımlar açısından en zengin olan ilk bölgedir. Pamukkale Üniversitesi kampüs alanı, çamlık parkı, teleferik, açık hava tiyatrosu, yoğun olarak kullanılan forum alışveriş merkezi, Bağbaşı vadi parkı ve çok sayıda ticaret alanının bulunduğu bölgedir.
2. Bölge Etki alanı en fazla olan ikinci bölgedir. Denizli'nin kent içinde bulunan ve en önemli su kaynağı olan Recep Yazıcıoğlu su toplama havzası ve göletini içine almaktadır. Bu bölge kent merkezinin kuzey doğu bölgesinde yer almaktadır. Alan hem kent merkezine yakın hem de tarımsal desenin yoğun bir şekilde görüldüğü bölgeye yakın olması açısından önemli bir bölgedir. Bu bölge kentin iklimini ve sosyokültürel aktivite çeşitliliğini etkileyen önemli bir su kaynağına sahiptir. 
3. Bölge: sosyal donatı alanları açısından zengin olan bölgedir. Denizli Büyükşehir Belediyesi, Ulu Cami, Stadyum ve yeşil yol güzergâhının başlangıç odağı olan Recep Yazıcıoğlu Parkını içine alan bölgedir. Recep Yazıcıoğlu Parkı yeşil yol sisteminin başlangıç odağıdır.

4. Bölge: Kentin güneydoğusunda yer almaktadır. Sosyo-ekonomisi tarım ve hayvancılığa dayalıdır. Tarım arazilerinin fazla olduğu bölge, kırsal peyzaj özellikleri açısından zengindir. Kırsal karakterinden dolayı insanların dinlenme, doğayla buluşma amacıyla tercih etmeye başladıkları bölgedir. Alanda yer alan hobi bahçeleri, alabalık tesisleri, doğayla iç içe olan gastronomi birimleri, Gökpınar Deresinin varlığı, ATV turu, trekking gibi aktivitelerin yapılabilmesi bölgeyi çekici hale getirmektedir.

5. Bölge: kentin girişinde ana ulaşım odaklarından birisi olan üçgen kavşağı ile yakın çevresindeki otogar, tarihi Kaleiçi çarşısı ve Denizli Valiliğini kapsayan bölgedir. Bu bölge İzmir, Afyon, Antalya illerinden gelen ulaşım bağlantılarıyla kentin giriş kapısı niteliğindedir. Ayrıca tarihi Kaleiçi, Denizli valiliğinin bu bölge de bulunması kentin tarihi ve kültürel özelliklerini yansıtmaktadır. Bölge oluşum itibariyle kentin çekirdeğidir.
6. Bölge: Birinci ve üçüncü bölgeler birbirine bağlayan bağlantı bölgesidir. Alanda kent içi parkların bir diğeri olan çamlık parkı, Forum Avm, açık hava tiyatrosu bulunmaktadır. Bu alan sosyo kültürel aktiviteler için önemli bir bölgedir. Ayrıca batısı askeri alandır ve bu eşik yapılaşmayı sınırlamakta aynı zamanda bölgenin de fiziksel sınırı olmaktadır.

7. Bölge: Alan kullanımları ve etki alanları açısından birinci ve dördüncü bölge arasında yer alan geçiş bölgesidir. Bu bölge kent merkezi ile kırsal dokunun arasında kalan, yapılaşmanın seyrekleşmeye başladığı, insanları doğayla buluşturmaya başladığı bölgedir. Kentle kır arasında bir bağlantı bölgesidir. Bu alanda tarım arazilerinin yoğunluğu artmakta ekonomisi tarım ve hayvancılığa dayanmaktadır. Tarım ve hayvancılığa yönelik organik ürünlerin doğal ortamından temin edilebileceği bir bölgedir. Bölgede ATV sporları, rekreasyon alanları, manzara seyir alanları bulunmaktadır.

$\mathrm{Bu}$ bölgeleme ve kullanımlar dikkate alınarak yeşil yol sistemi kurgulanmış, gerekli bağlantılar güçlendirilmiştir.

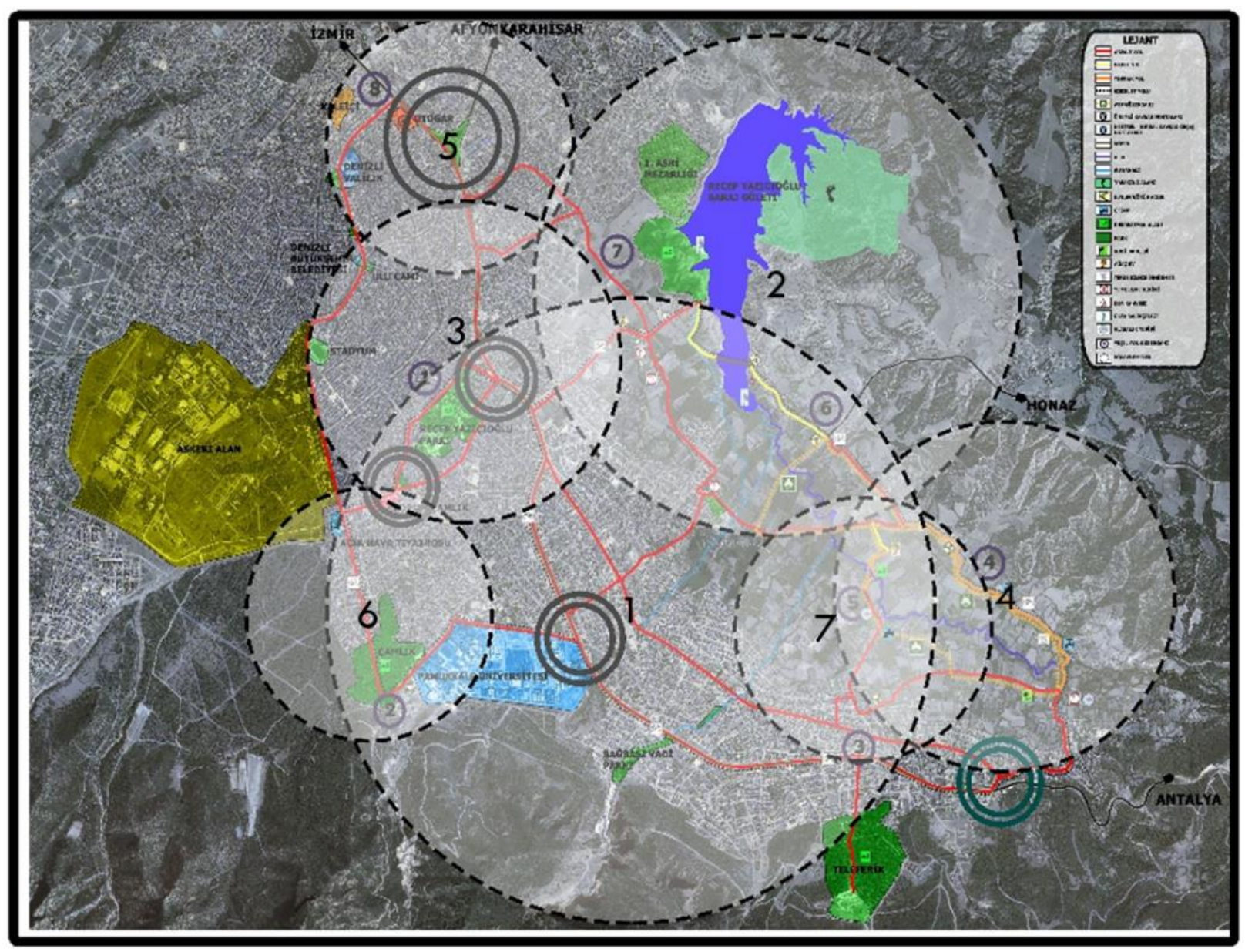

Şekil 2. Odak noktaları, bölgeler ve etki alanları 
Kent merkezinde yer alan Recep Yazıcıoğlu Parkı, Üniversite kampüsü, Bayramyeri ve Çınar meydanına yakın mesafede bulunan önemli odaklar ve izleri takip ederek Recep Yazıcıoğlu Göleti'ne bağlanmıştır. Söz konusu bağ mevcut bisiklet yollarının uygun genişlik ve dokuya sahip olan yollara getirilen öneri bisiklet yoluyla sürdürülebilir dolaşım sağlanmıştır. Yeşil yol bağlantısı aynı zamanda kent içinde ana ulaşım akslarında önemli bir peyzaj düzenlemesi sonucu oluşan çizgisel izler olan refüjlerle de sağlanmıştır.

$\mathrm{Bu}$ bölgeleme ve kullanımlar dikkate alınarak kurgulanan yeşil yol ağı 1/5000 ölçekli planda sadece iki, dört ve yedinci bölgelerinde yer alan 4-5-6 nolu yeşil yol gü- zergahları ayrıntılı olarak incelenmektedir. Bu doğrultuda aşağıda belirtildiği gibi 4-5-6 nolu yeşil yol güzergahları planlanmıştır.

- 4 nolu güzergahı kapsayan bölge: tarımsal desen ve doğal peyzaj öğelerinin yoğun olduğu doğal koridor ve manzara bölgesi, (Şekil 3)

- 5 nolu güzergahı kapsayan bölge: kent merkezini tarımsal desenle buluşturan geçiş bölgesi, (Şekil 4)

- 6 nolu güzergahı kapsayan bölge: Recep Yazıcıoğlu Göleti ve çevresi eğlence, dinlenme vb. rekreasyonel aktivite bölgesi olarak tanımlanmıştır (Şekil 5).
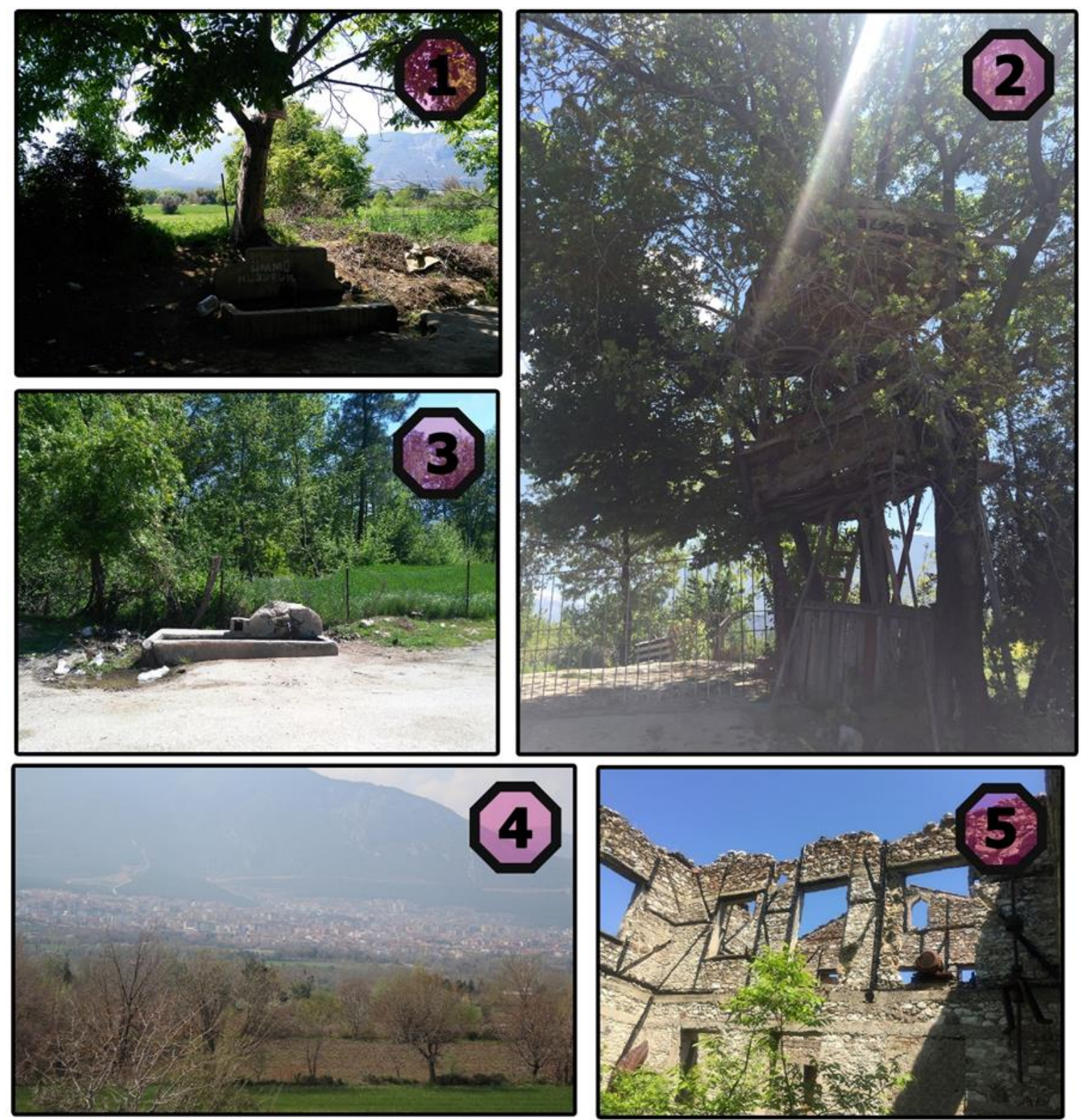

Şekil 3. Tarımsal Desen ve Doğal Peyzaj öğelerinin yoğun olduğu doğal koridor ve manzara bölgesi 

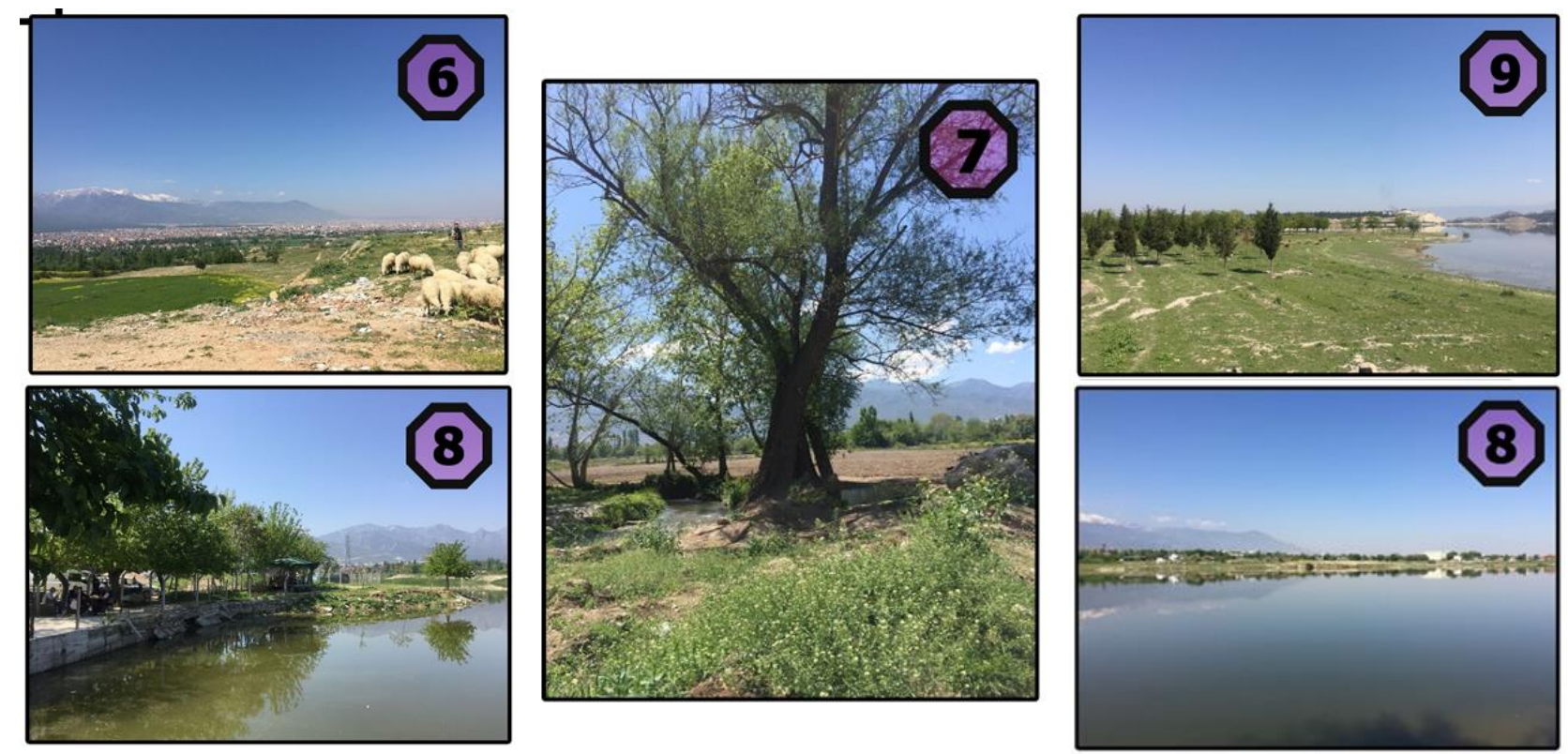

Şekil 4. Kent Merkezini Tarımsal Peyzaj deseni ile bütünleştiren bölge
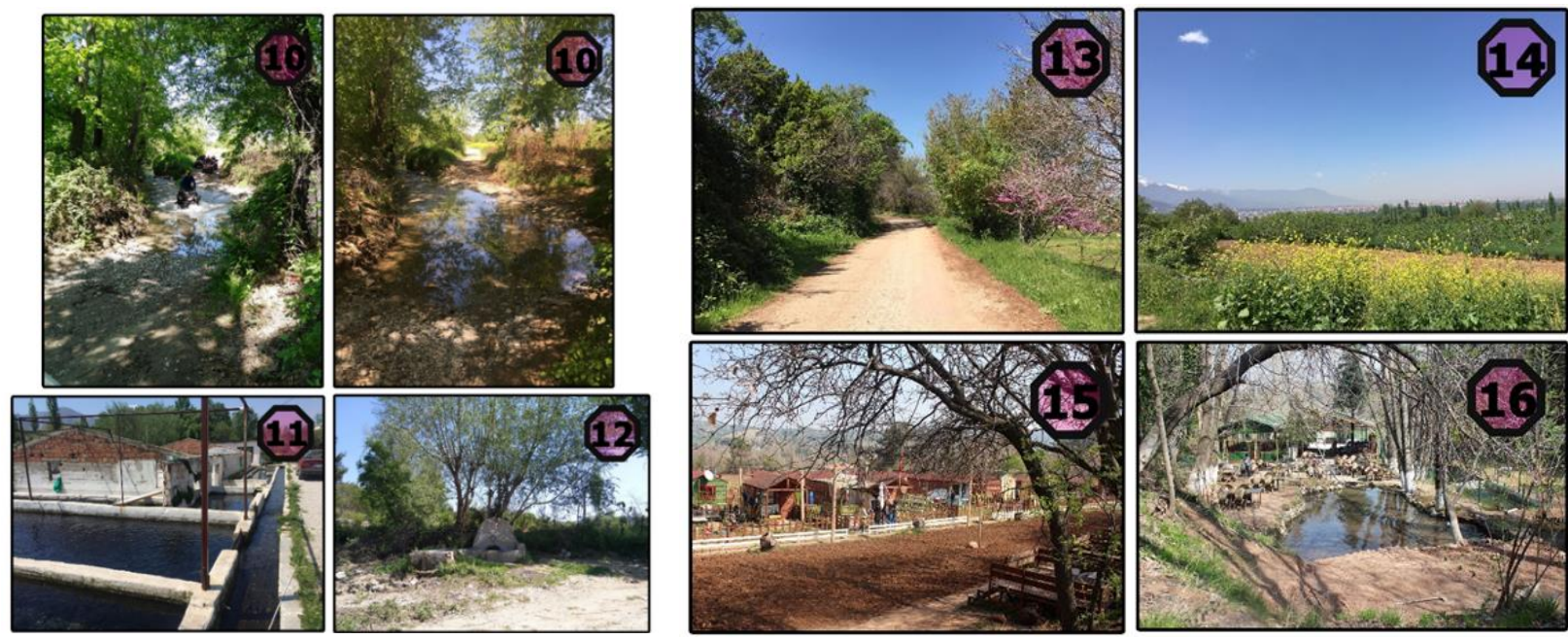

Şekil 5. Recep Yazıcıoğlu göleti ve çevresi eğlence, dinlenme vb. rekreasyonel aktivite bölgesi

\section{SONUÇLAR}

Denizli Pamukkale ilçesi örneğinde Recep Yazıcıoğlu Göleti güneydoğusu ile Tekkeköy arasındaki arazi, Recep Yazıcıoğlu Göleti ile kentsel doku sınırı olan araziler yapılaşmanın olmadığı ancak tarım alanları, bağ, bahçe, yeme-içme, eğlence ve spor alanlarının yoğunlukta olduğu kır kent ayırım noktasında kalan kentin hemen bitişiğindeki doğal yapısı bozulmamış değerli bir alan niteliğindedir. Bu alan kendi içerisinde değerlendirilerek 4,5 ve 6 nolu bölge olarak yeşil yol güzergahları olarak belirlenmiş ve yeşil yol planına dahil edilmiştir (Şekil 6). Kentin hemen bitişiğindeki bu değerli alanlar hızlı kentleşme nedeniyle ileride yerleşim intiyacı kapsamında maalesef ilk düşünülen alanlar olabileceği için, koruma- kullanma dengesi kapsamında yeşil yol planına dahil edilerek önemi vurgulanmış ve kentin yeşil altyapı sitemi ile entegrasyonu sağlanmıştır. Kentin hemen bitişiğindeki bu alan farklı rekreasyonel aktivitelerede olanak sağlamaktadır. Alanın kente yakın olması sebebiyle ulaşılabilirliği çok yüksektir. ATV kullanıcılarının bu alanlarda rekreasyonel amaçlarla kullandıkları güzergahlar tespit edilerek yeşil yol planına dahil edilmiştir. Tarım alanları, bağ ve bahçe arazileri nedeniyle mevsime bağı olarak farklı meyve ve sebzeyi dalında toplama, ağaçlarla çevrelenmiş yollarda bisiklet sürme, piknik yapmak, spor yapmak, dinlenmek, alabalık çiftliklerini-hobi bahçesini-tarihi değirmeni-ağaç evi gezmek, yeni yerler keşfetmek gibi farklı aktivitelerin yapılabileceği rekreasyonel 
potansiyelin yüksek olduğu alanlardan geçen güzergahlar olarak yeşil yolu şekillendirmiştir.

Çalışma kapsamında belirlenen güzergahta bulunan doğal, kültürel ögeler Şekil 6'da ve öneri yeşil yol tasarımı kullanımlar Şekil 7'de verilmiştir.
Denizli Pamukkale ilçesi örneğinde yeşil yol güzergahlarında arazi yapısına uygun olacak şekilde çalışma kapsamında tespit edilen bazı noktalarda tasarım önerileri de ortaya konulmuştur (Şekil 8).

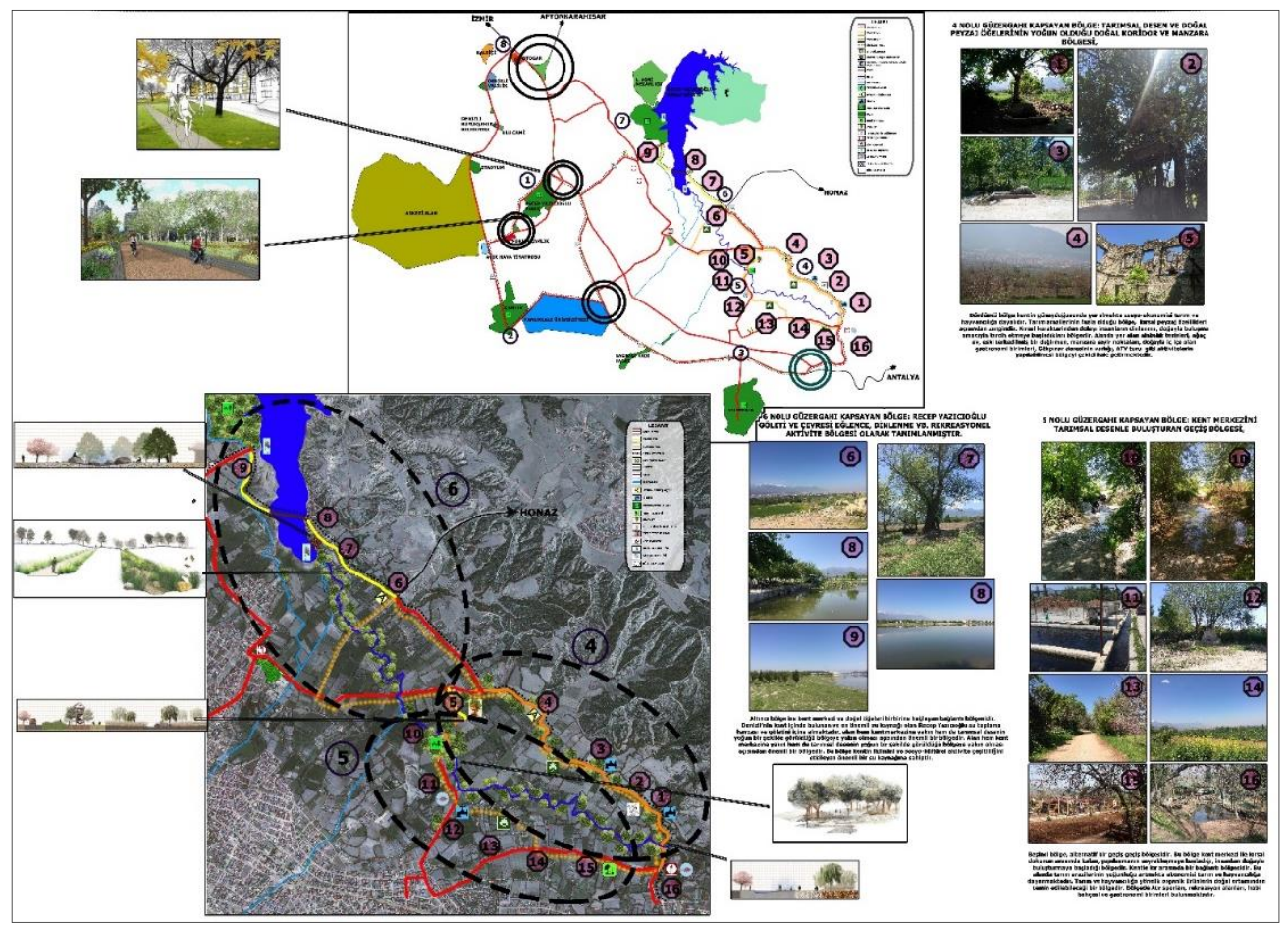

Şekil 6. Yeşil yol güzergahı ve doğal kültürel ögeler

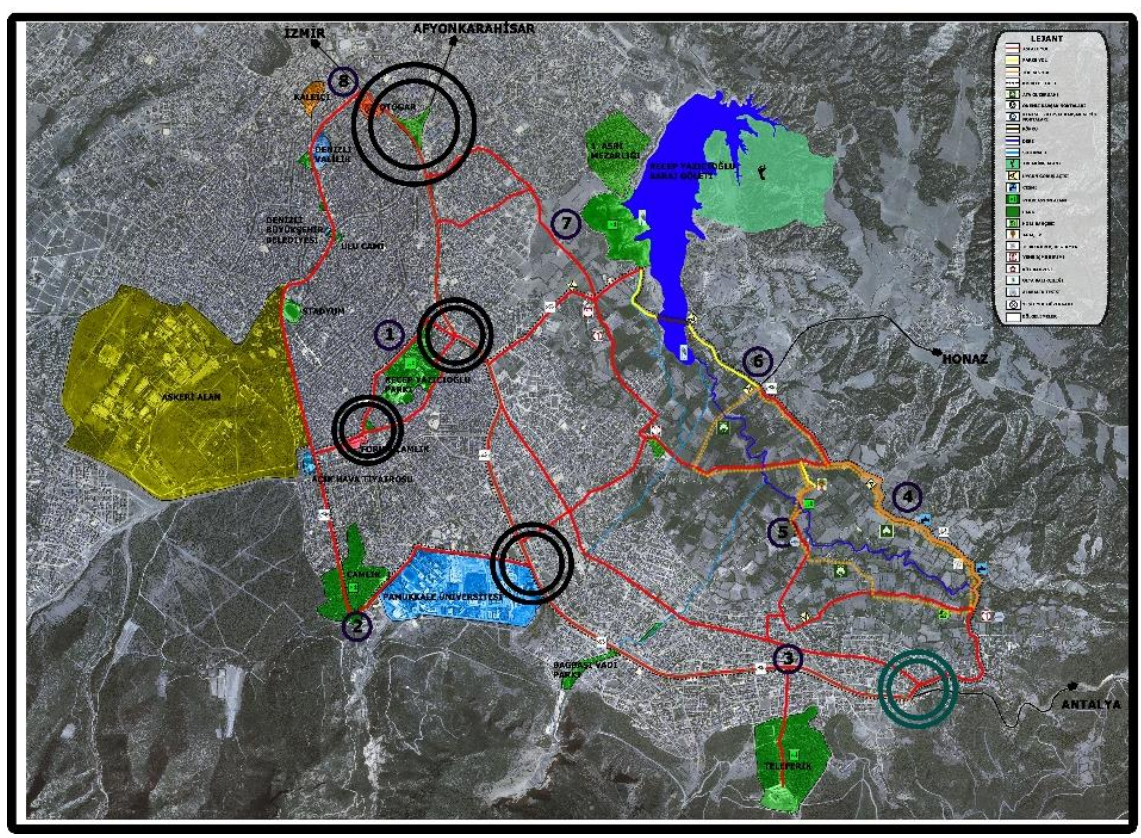

Şekil 7. Potansiyel yeşil yol güzergahı 



Şekil 8. Yeşil yol güzergahı tasarım önerileri

Bu çalışma ile Pamukkale ilçesinde yer alan doğal ve kültürel kaynaklar koruma-kullanım dengesi çerçevesinde ele alınarak yeşil altyapı sistemi ile entegrasyonu sağlanmıştır. Çalışma ile bir yandan kentteki yeşil dokunun sürekliliği sağlanırken, bir yandan da kentte yaşayanlar için alternatif rekreasyon alanlarının oluşumuna katkı sunulmuştur. Günümüz kentlerindeki artan kirlilik, yüzey akış kontrolünün sağlanamaması, yeşil dokuya ve kentin diğer mekanlarına erişimdeki zorluklar planlamadan kaynaklı eksiklikler olarak karşımıza çıkmaktadır.
Bu yüzden tüm ölçeklerde yapılacak planlama çalışmalarına ve plan kararlarına yeşil yol planları dahil edilmesi oldukça önem arz etmektedir.

\section{TEŞEKKÜR}

Pamukkale Üniversitesi Mimarlık ve Tasarım Fakültesi, Şehir ve Bölge Planlama Anabilim Dalı yüksek lisans öğrencileri Ece Aslan, Ayça İlhan, Seçil Akay, Havva Sözeri, Cansu Nur Otçu, Dilara Efe'ye teşekkür ederiz. Bu çalışmaya 2019KRM004-003 nolu proje ile destek veren 
Pamukkale Üniversitesi Bilimsel Araştırma Projeleri Koordinatörlüğüne katkılarından dolayı teşekkür ederiz.

\section{KAYNAKLAR}

Ahern, J. (1995).Greenways as a planning strategy, Landscape and Urban Planning, 33 (1995), 31-155

Associazione Italiana Greenways, (1999). Regolamento dell' Associazione Italiana Greenways, Milano.

Bryant, M. M. (2006). Urban landscape conservation and the role of ecological greenways at local and metropolitan scales, Landscape and Urban Planning, 76 (2006), 23-44

Doğan, D. (2012). Malatya İli Kapsamında Peyzaj Koridoru Kavramının İrdelenmesi, Yüksek Lisans Tezi, Ankara Üniversitesi Fen Bilimleri Enstitüsü Peyzaj Mimarlığı Anabilim Dalı, Ankara

Fabos, J.G. (1995). Introduction and overview: the greenway movement, uses and potentials of greenways, Landscape and Urban Planning 33 1-13

Fedorowick, J.M. (1993). A landscape restoration framework for wildlife and agriculture in the rural landscape, Landscape and Urban Plann., 27 (1993), pp. 7-17

Forman, R., Godron, M. (1986). Landscape Ecology, Wiley, New York, $619 \mathrm{pp}$.

Gobster, P. H. (1995). Perception and use of a metropolitan greenway system for recreation, Landscape and Urban Planning, 33, 401-413

Groome, D. (1990). Green corridors: a discussion of a planning concept, Landscape and Urban Planning, 19(4),383-387

Kerkstra, K., Vrijlandt, P. (1990). Landscape planning for industrial agriculture: a proposed framework for rural areas, Landscape and Urban Plann., 18: 275-287.
Little, C. (1990). Greenways for America, Johns Hopkins University Press, Baltimore, MD, 207 pp.

Maryland Department of Natural Resources, (2003). Greenways: Making Natural Connections (http://dnr.state.md.us/greenways/) accessed, 9-20-03.

Porter, E., Hastings, W. (1991). Metropolitan greenways: green connections for urban areas, Trends, 28(4): 14-17.

Ryder, B. A. (1995). Green way planning and growth management: partners in conservation? Landscape and Urban Planning, 33 (1995), 417-432

Searns, R. M. 1995. The evolution of greenways as an adaptive urban landscape form, Landscape and Urban Planning 33:65-80.

Sijmons, D. (1990). Regional planning as a strategy, Landscape and Urban Plann., 18: 265-273.

Smith, D.S. (1993). An overview of greenways: their history, ecological context and specific functions, In: Smith, D.S., Hellmund, P.C. (Eds.), Ecology of Greenways: Design Functions of Linear Conservation Areas, University of Minnesota Press, Minneapolis, pp. $1 \pm 22$

Toccolini, A., Fumagalli, N., Senes, G. (2006). Greenways planning in Italy: the Lambro River Valley Greenways System, Landscape and Urban Planning 76, p 98-111

Van Buuren, M. (1991). A hydrological approach to landscape planning: the framework concept elaborated from a hydrological perspective, Landscape and Urban Plann., 21: 91 107.

Viles, R.L., Rosier, D.J. (2001). How to use roads in the creation of greenways: case studies in three New Zealand landscapes, Landscape and Urban Planning, 55, 15-27.

Zube, E. H. (1995). Greenways and the US National Park System, Landscape and Urban Planning, 33(1995) 17-25. 